\title{
Learning Preferences among Students
}

\author{
Veena ${ }^{1}$, Shailaja Shastri ${ }^{2}$ \\ ${ }^{1}$ (Research Scholar, Department of Psychology, Jain University, Bangalore, India) \\ 2 (Professor \& Head, Department of Psychology, Jain University, Bangalore, India)
}

\begin{abstract}
The present study investigated preference of four different modes of learning among under graduate students of pure science and applied science courses in Bangalore city. The respondents were divided into two groups - high and low academic achievement, based on their previous semester results. Gender was also considered for the analysis. The tool used for the present study was VARK Questionnaire (Version 7.0), (Fleming, 2001). For non-normal variable, Mann Whitney U and Kruskal Wallis were utilized to test various hypotheses of this study. The study revealed that, $80 \%$ of the students preferred single mode of information presentation, with a preference towards visual mode (3\%), auditory mode $(43 \%)$, reading/writing mode $(7 \%)$, kinesthetic mode (27\%). 20\% preferred multiple modes [2 modes (17\%), 3 modes (2\%), and 4 modes (1\%)]. Pure science and applied science course students differ significantly in their preference for visual learning style. There was no significant difference in learning style preference between high and low academic achievement students. Gender differences show that boys and girls differed significantly in their preference for auditory and reading learning styles.
\end{abstract}

Keywords: VARK (Visual, Auditory, Reading/Writing and Kinesthetic), Learning style, Academic achievement, Pure Science and Applied Science.

\section{Introduction}

The genesis of learning dates back to many centuries. Informal learning process is as old as the origin of mankind. The learning processes through mere observations and practice have transitioned through various stages. Holistic learning through semi formal means like "Gurukul" system marked the beginning of learning through imparting of education. The creative effects of learning and the overbearing significance of appropriate education system to facilitate meaningful learning were well realized by our older generations. The teaching processes, learning methods and gainful application of the knowledge imbibed have evolved over many generations. The learning process in the education system has attained more significance over the recent years. The awareness of the psychological aspects of the learning process helps in more thorough analysis of an education system. Due emphasis in identification of influencing variables in the learning process, scientific analysis of the effect of each of such variables on the learning process and application of the results inferred through such studies have contributed in further refinement of the education system, in general and learning processes, in particular. According to Heffler (2001) "It is advantageous to know your learning style when approaching a new learning situation to optimize the outcome" and added that awareness of learning styles of the students support the teachers' efforts to organize the course content for better learning to occur. (cited in Pallapu 2008).

This paper details an analytical study carried out on the learning patterns of college students pursuing two different streams in our current education system, namely pure science faculty and applied science faculty. The result of the study is also critically reviewed from the perspective of learning process demonstrated by the two different genders, namely male students and female students. The learning pattern exhibited by the students with low academic performance in pure science stream and applied science stream vis a vis the students with high academic performance in both these streams is also analyzed.

The study was carried out among the college students in Bangalore City, who are pursuing their under graduate program in pure science stream and in applied science stream. Pure science and applied science streams have many commonalities in their curriculum, and yet have two different learning patterns. Therefore these two closely related streams were selected to achieve more concise and decisive inferences from the study. While pure science stream deals with a more theory oriented curriculum, the applied science stream, as the name indicates, need to learn the theory with an ultimate objective of applying the scientific theories for solving practical engineering challenges. As it could be seen, the conceptual skills, analytical abilities and problem solving abilities which are required to be imbibed by the students of the applied science stream vary much from that of the students of pure science stream. 
The aim of examining the results of this study from the perspective of gender of the students is to analyze whether the students from different genders orient their learning pattern in any significantly different manner to address the learning needs entailed in pure science faculty and in applied science faculty.

The study also focused on analyzing how the under performers fared in both pure science stream \& applied science stream when compared to the academically sound students in the respective stream. During the interaction with professors and students, it was revealed and It is worthwhile to note here that the curriculum in different years of study of these science streams (whether pure science or applied science) are closely related to one another, thereby warranting the students to have a concurrent approach and continuity in their studies. Thus, it is very likely that a student not gaining sufficient knowledge in the first year may not be able to perform better in the subsequent years, unless a very conscious effort is made by the student to bridge the gap in his knowledge. Thus, the study tends to indicate that the underperforming students in both these science streams under review continued to remain so.

The results of the study can be extrapolated towards understanding the psychological factors influencing the learning process of the college students of pure science faculty $\&$ applied science faculty and for the overall benefit of education community by adopting appropriate refinements in the teaching \& learning processes.

\subsection{Objective of the Study}

\section{Methodology}

The present study aims at determining the significant differences in learning style preferences among under graduate students' based on course/discipline (pure science and applied science) academic performance (high and low) and gender (boys and girls).

\subsection{Operational Definition}

\subsubsection{Learning style}

Learning styles are the preferences in which the information is taken-in and given-out. (Fleming 2001).

\subsubsection{Pure science and applied science}

The students are drawn from two faculty/disciplines (pure science and applied science). Pure science students are from undergraduate colleges, affiliated to Bangalore University, studying in II/III/IV semester Bachelor of Science (B.Sc.) and opted for Physics, Chemistry, and Mathematics (PCM) combination. Applied science students are from undergraduate colleges, affiliated to Visweshwaraya Technological University, studying in II/III/IV semester Bachelor of Engineering (B.E) and who have opted for computer science and information technology.

\subsubsection{Academic achievement}

Examination is used to gauge how far and how much the learning objectives have been achieved. It acts as a benchmark to qualify students to enter university or apply work either in the public sector or private firms. In this study, students' academic achievement is based upon the final end semester examination result (based on theory, practicals and internal assessment) marks were obtained from the educational institution/students marks sheet. During the interview researcher also obtained the information from the students regarding their previous semester results to come to the conclusion on the performance of the students stated here for the purpose of the study. Educational institution considers the total marks obtained in each semester examination to declare their academic achievement, where a score of $70 \%$ and above are considered distinction, $50 \%$ and below are considered as pass class. In the present study the same criteria is considered to determine the academic achievement. Students who have scored $70 \%$ and above were considered as "high academic achievers" and 50\% and below were considered to be "low academic achievers".

The specific hypotheses formulated were:

\section{Hypotheses}

H1. Pure science and applied science course students do not differ significantly on learning styles.

H2. High and low academic achievement students do not differ significantly on learning styles.

H3. Boys and girls do not significantly differ on learning styles.

The research is exploratory in nature.

\section{Research Design}


Participants

\section{Method}

Participants comprised 656 under graduate college students. Aged 18-26 years, from pure science, three undergraduate colleges and five engineering colleges from applied science in Bangalore city took part in the present study. Among the 656 participants, 48\% were from pure science course and 52\% were from applied science course. Boys constituted 47\% and girls 53\%. Academic achievement was also considered - high academic achievement students constituted $38 \%$ of the participants, and low academic achievement students made up $22 \%$.

\section{Tools}

Socio-demographic data sheet was used to obtain the information about the subject's age, education, gender, class, college and family income.

\section{$>\quad$ VARK Questionnaire (Version 7.0), (Fleming, 2001)}

VARK provides the learning preferences. VARK stands for Visual, Aural, Read/write, and Kinesthetic sensory modalities that are used for learning information.

Visual (V):This preference includes the depiction of information in maps, spider diagrams, charts, graphs, flow charts, labeled diagrams, and all the symbolic arrows, circles, hierarchies and other devices. spoken."

Aural / Auditory (A): This perceptual mode describes a preference for information that is "heard or

Read/write (R): This preference is for information displayed as words. This preference emphasizes text-based input and output - reading and writing in all its forms.

Kinesthetic $(\mathrm{K})$ : By definition, this modality refers to the "perceptual preference related to the use of experience and practice (simulated or real)."

The reliability of the scale for visual, auditory, reading and kinesthetic is $0.85,0.82,0.84$, and 0.77 respectively.

\section{Procedure}

The researcher obtained permission from the educational institutions to collect data from the students. Participants were recruited by class as a unit and groups of 35-40 students filled out the questionnaires. Prior to responding to the questionnaires, the consent form was filled and an interactive orientation briefing was organized for the students regarding the purpose of the study and the need to answer all the questions frankly.

\section{Results and Discussion}

The present study investigated the learning preferences among pure science and applied science course students, academic achievement (high and low) and gender differences (boys and girls). The responses of the students were analyzed to meet the objectives of the study. Descriptive statistics, and for non- normal variable non parametric tests like Mann Whitney U test and Kruskal Wallis tests were used for comparison.

Figure 1: Distribution or trends of learning preference of the respondents.

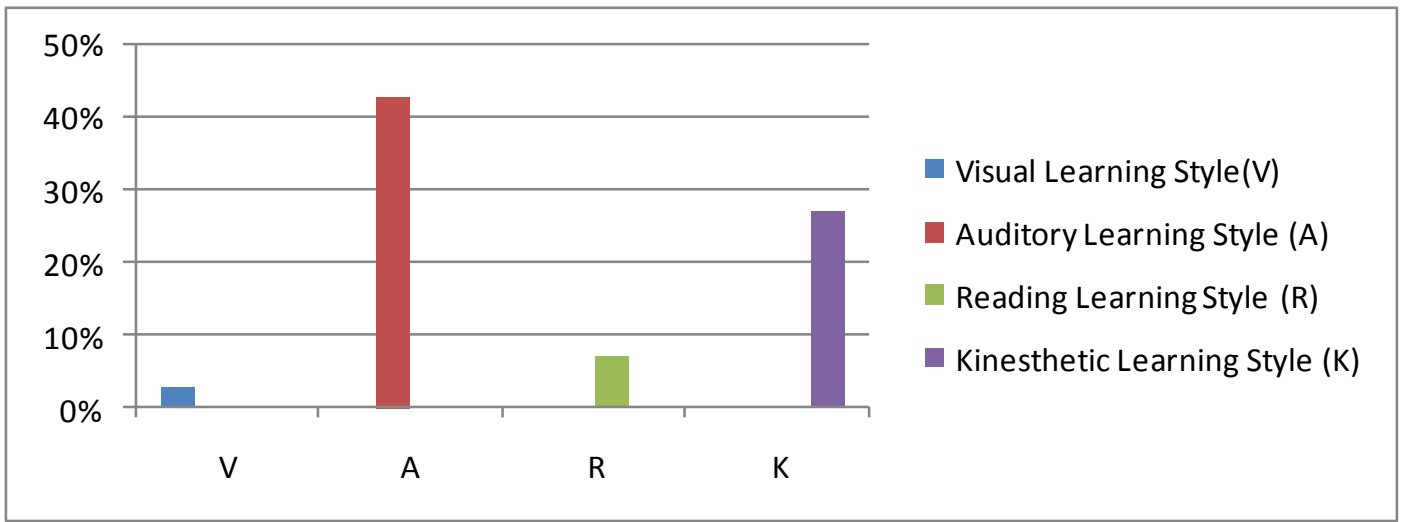


Figure 2: Distribution or trends of learning preference of the respondents on different modes/patterns.

$100 \%$

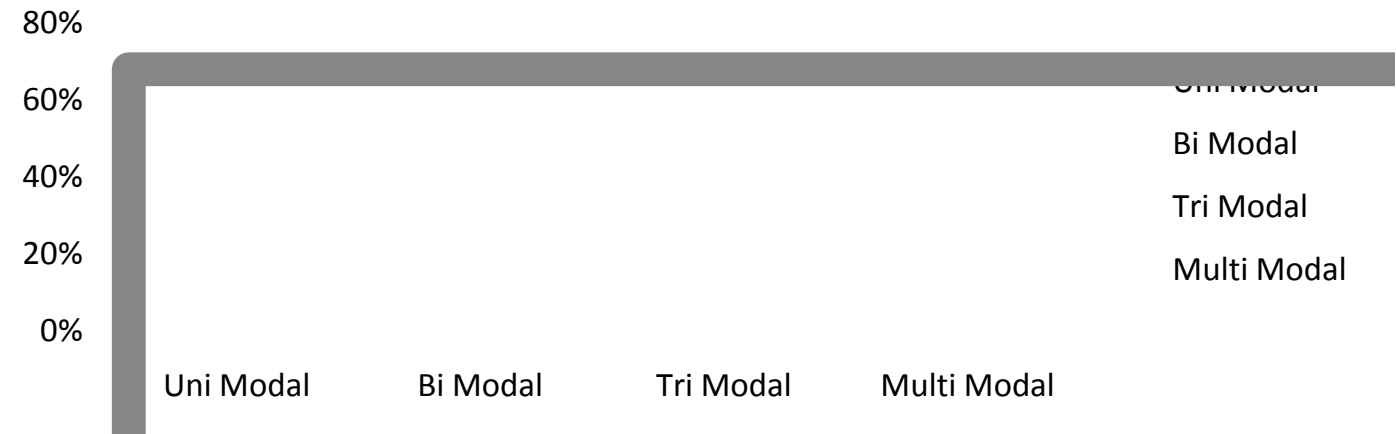

Figure 1 and 2 presents the percentages of students who preferred visual, auditory, reading/writing and kinesthetic modes of learning. Among 656 under graduate students, $80 \%$ of the students preferred a single mode of information presentation, visual mode (3\%), auditory mode $(43 \%)$, reading/writing mode $(7 \%)$ and kinesthetic mode (27\%). Furthermore $20 \%$ preferred multiple modes [2 modes $(17 \%)$, 3 modes $(2 \%)$, and 4 modes (1\%)]. The majority of college students preferred single-mode of instruction with a preference towards auditory learning style. Of the students who preferred a single mode of information presentation, $43 \%$ preferred receiving information by speech - which arrives to the learner's ear and is therefore coded as auditory by the questionnaire. Similarly, only 7\% revealed a preference for accessing information from printed words; discussions, these students were coded as reading/writing learners because they use reading and writing as their preference for taking in information. Only 3\% preferred the visual mode and these students preferred information to arrive in the form of graphs, charts and flow diagrams. Twenty seven percent of the students preferred learning by using all their senses, described as kinesthetic learning preference. These students prefer concrete, multisensory experiences in their learning. Abidin et al., (2011) also found similar results in his study that majority preferred auditory learning style which consisted of $61 \%$ of total students.

According to Bowen (1982), "students below the top levels of achievement on scholastic aptitude test scores, when taught in their preferred style, can rise to high levels of academic achievement". He also asserted that virtually all people are educable, can aspire to become educated persons, and should be educated. He was careful to point out that human beings are educable "in different degrees proportionate to difference in their native endowments". Therefore it is important to know the learning styles of students and design the teaching method to suit the students learning style. Claxton \& Murrell (1987) states that individual learners have their own preferred learning styles and that teachers have some responsibility for gearing up their teaching style to fit the preferred learning style of learners. (cited in Goodwin 1995). Dunn et al., (1981) discussed that we can no longer afford to assume that all students will learn through whichever strategy the educators prefer to use.

In contrast, the traditional lecture method assumes that many students prefer auditory learning style to learn. In addition, the traditional lecture method assumes that most of the students acquire information presented verbally at the same pace without having any communication with the presenter/educator. The current study clearly indicates that the majority of students prefer auditory learning style; Both quantitative survey data and open ended qualitative student reports suggests that students are taught only through the lecture method and not any other method by their faculty. This may be because in many universities, faculties utilize lecture method, which is a conventional technique to teach students. When a student community has been conditioned to the conventional method, there is least utilization of other styles -visual, reading/writing and kinesthetic. There are numerous studies that indicate the importance of utilizing multi-modal learning styles. Dunn et al (1989) states that students with multiple learning styles tend to gain more and obtain higher scores compared with those who rely solely on one style. According to Felder (1995) students learn more when information is obtainable in a variety of approaches than when only a single approach is applied. He also states that most educational psychologists are of the opinion that multiple learning styles can significantly enhance academic achievement. (cited in Abidin et al). Lujan \& DiCarlo (2005) reflects that most students are able to learn effectively as long as educators provide a blend of visual, auditory, reading/writing and kinesthetic activities. However, some students prefer one of the modalities over the other three so strongly that they struggle to understand the subject matter unless special care is taken to present it in their preferred mode. Therefore, students should engage in multimodal learning styles and educators should motivate and imbibe the importance of using all the modalities to enhance students' academic achievement. 


\subsection{Testing of Hypothesis 1}

H1 Pure science and applied science course students do not differ significantly on learning styles.

To explore the significance of differences in learning styles of pure science and applied science course students Mann Whitney U test was computed for non normal variables and the results are presented in Table 1.

Table 1 Descriptive statistics and Mann Whitney $U$ test for learning styles among pure and applied science course students.

\begin{tabular}{|c|c|c|c|}
\hline \multirow{3}{*}{ Learning styles } & & ine & \multirow{3}{*}{ P value } \\
\hline & Pure science $(\mathrm{N}=339)$ & Applied science $(\mathrm{N}=317)$ & \\
\hline & \multicolumn{2}{|c|}{ Mean \pm SD } & \\
\hline Visual & $3.67 \pm 2.41$ & $4.27 \pm 2.47$ & $0.001^{* *}$ \\
\hline Auditory & $7.19 \pm 2.67$ & $7.46 \pm 2.80$ & 0.252 \\
\hline Reading & $5.04+2.40$ & $4.92+2.37$ & 0.655 \\
\hline Kinesthetic & $6.37 \pm 2.53$ & $6.50 \pm 2.74$ & 0.460 \\
\hline
\end{tabular}

Table 1 shows the results of two groups who opted for two different courses/disciplines (Pure science and applied science) with regard to learning styles. The results indicate a statistically significant difference in visual learning style among pure science and applied science course students. From table 1 it can be inferred that applied science course students preferred more of visual learning style, compared with pure science course students that is, applied science students prefer to use diagrams and symbolic devices such as graphs, flow charts, hierarchies, models and arrows that represent printed information. Hence we reject the null hypothesis and accept the alternate hypothesis which states pure science and applied science course students differ significantly on learning styles. The finding is supported by the study conducted by Hativa and Birenbaum (2000) mentioned that there were discipline-related differences in student's learning preferences inspite of different learning environments. Khalid et al (2013) in his study cites that based on the findings of a research done on engineer and science students in Aalborg University, Kolmos and Holgaard (2008) said that the students were more active, more visual and sensitive towards the teaching and learning sessions.

\subsection{Testing of Hypothesis 2}

H2: High and low academic achievement students do not differ significantly on learning style.

To test the significance difference in learning style between high and low academic achievement students, Kruskal Wallis test was computed. The results are presented in Table 2.

Table 2 Descriptive statistics and Kruskal Wallis test values on different learning styles between high and low academic achievement students.

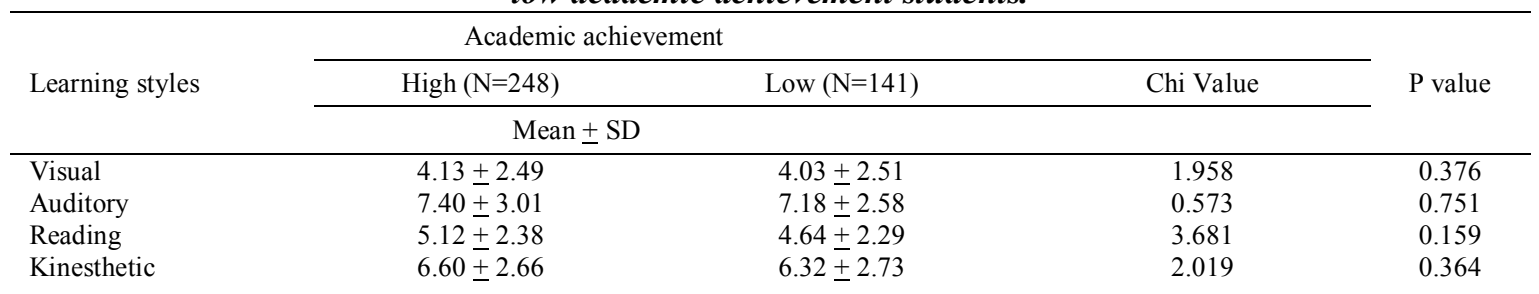

The chi square values in table 2 clearly indicate that the learning styles do not significantly differ between high and low academic achievement students. Therefore, the null hypothesis is accepted which states that there is no significant difference in learning styles between high and low academic achievement students. When we examine the mean and standard deviation of high and low academic achievement groups on learning style, it can be inferred that high academic achievement students have more preference for reading learning style when compared to low academic achievement students. A similar trend of conflicting results has been found in investigations of the relationship between learning preferences and academic performance. Farrell, Moskwa \& Claire (1992); studied the relationship between learning style and academic achievement. Results indicated that overall, there was a negligible relationship between learning style and academic achievement but there did seem to be a relationship between certain learning styles and academic performance when examined on an individual basis. Abidin et al (2011) denote that there is not much difference in preference for learning dimension among high, moderate and low achievement groups. Dobson (2010) mentions in his study that Baykan \& Nacar (2007) found no relationship between VARK modality preferences and grade point average, but Alkhasawneh et al. (2008) did find a significant relationship between VARK preferences and course grades. According to Goodwin (1995) students learning style was related to students' achievement. According to Khalid et al (2013) students 
who employ effective learning styles usually obtain excellent academic achievement and are able to secure a place in higher institutions or a position in the work sector.

\subsection{Testing of Hypothesis 3}

H3: Boys and girls do not significantly differ on learning styles.

To explore the significance difference between gender and learning styles, Mann Whitney U test was computed and the results are presented in Table 3.

Table 3 Descriptive and Mann Whitney $U$ test scores for learning styles among boys and girls.

\begin{tabular}{llrc}
\hline & Boys $(\mathrm{N}=305)$ & Girls $(\mathrm{N}=351)$ & \\
\cline { 2 - 5 } Learning styles & & Mean $+\mathrm{SD}$ & \\
\hline Visual & & $4.01+2.48$ & 0.795 \\
Auditory & $3.95+2.43$ & $7.74+2.85$ & $<.001^{* *}$ \\
Reading & $6.86+2.53$ & $5.34+2.37$ & $<.001^{* *}$ \\
Kinesthetic & $4.57+2.33$ & $6.44+2.55$ & 0.760 \\
\hline
\end{tabular}

$* * \mathrm{p}<.001$ (Significant)

The results reveal that there is a significant difference in learning styles among boys and girls. The results clearly state that girl's preferred receiving information by speech, which arrives to the learner's ear (auditory). The results also revealed girls' preference for accessing information from printed words (reading/writing) to take in information. The findings is supported by the previous research work by Dobson (2010) in his study cites two of the studies (Alkhasawneh et al. 2008; Slater et al. 2007) which found no significant differences in preferences between men and women, whereas one study (Wehrwein et al. 2007) did report a difference which was descriptive in nature and was not supported by statistical analysis. Also Dobson (2010) in his study found a significant trend in sensory modality preferences and sex.

From the findings it can be concluded that:

\section{Conclusion}

- There was a significant difference in learning preferences between students of pure and applied science courses.

- There was a significant difference in learning preferences between boys and girls.

- There was no significant difference in learning style preferences between high and low academic achievement students.

\section{Limitations of the study}

This study has some limitations that merit consideration. namely,

1. The population is limited to pure science and applied science course students in Bangalore city.

2. The teaching style was not considered in the present study, as it also influences the learning styles of students.

3. The participants in this study were from middle to upper-middle class and upper class backgrounds residing in urban environment. Therefore these results can be generalized to similar population only.

\section{Implications}

A study/knowledge of students' learning preferences can help educators and students to improve the delivery of education and academic achievement respectively. The insights and new awareness gained will enable educators to understand and adjust the curriculum to fit the needs of students. This knowledge can also be utilized in planning a suitable intervention in the areas for students as well as educators.

\section{References:}

[1] Pallapu P. (2008). "An Exploratory Study of Undergraduate Students' Learning Styles", Doctoral dissertation, UMI No 3333140. Retrieved from http://etd.auburn.edu/etd/bitstream/handle/10415/1180/Pallapu Prasanthi 38.pdf?sequence=1.

[2] Fleming ND (2001) “Learning style questionnaire”. Retrieved from http://www.vark-learn.com/english/index.asp

[3] Abidin MJZ, Rezaee AA, Abdullah HN, \& Singh KKB. (2011) "Learning styles and overall academic achievement in a specific educational system". International Journal of Humanities and Social Science Vol. 1 No. 10; Retrieved from http://www.ijhssnet.com/journals/Vol_1_No_10_August_2011/19.pdf.

[4] Goodwin DD. (1995). "Effects of matching student and instructor learning style preferences on academic achievement in English", Dissertation and theses. Retrieved from Proquest database. (UMI No 9622393).

[5] Dunn R, De Bello, Brennan P, Krimsky J \& Murrain P. (1981), "Learning style researchers define differences differently ". Educational leadership. Retrieved from http://ascd.com/ASCD/pdf/journals/ed_lead/el_198102_dunn.pdf.

[6] Lujan, H.L \& DiCarlo, S.E., (2005) "First-year medical students prefer multiple learning styles", Advan in PhysiolEdu30:13-16; doi: 10.1152/advan.00045.2005. Retrieved from http://advan.physiology.org/content/30/1/13.full. 
[7] Hativa N \& Birenbaum M. (2000) "Who Prefers What? Disciplinary Differences in Students' Preferred Approaches to Teaching and Learning Styles", Research in Higher Education, April 2000, Volume 41, Issue 2, pp 209-236. Retrieved from http://link.springer.com/article/10.1023/A\%3 A1007095205308.

[8] Khalid et al (2013) "The Learning Styles and Academic Achievements among Arts and Science Streams Student", International Journal of Academic Research in Progressive Education and Development, Vol. 2, No. 2 ISSN: 2226-6348. Retrieved from http://www.hrmars.com/admin/pics/1774.pdf

[9] Farrell, Moskwa \& Claire. (1992) “The Relationship between Learning Style and Academic Achievement”. Dissertations/Theses. Retrieved from http://www.eric.ed.gov/ERICWebPortal/search/detailmini.jsp?_nfpb=true\&_\&ERICExtSearch_SearchValue_0=ED343081\&ERIC ExtSearch_SearchType_0=no\&accno=ED343081. / http://catalogue.nla.gov.au/Record/5541754

[10] Dobson JL. (2010) "A comparison between learning style preferences and sex, status and course performance". Retrieved from http://advan.physiology.org/content/34/4/197.full.pdf. 